\title{
Case Study of SEM-EDS Cross-Sections to Assist in Understanding p-XRF Results from William H. Johnson Paintings
}

Keara Teeter ${ }^{1}$, Natalie Mendez ${ }^{2}$, Gwen Manthey ${ }^{1}$, Amber Kerr ${ }^{1}$ and Thomas Lam ${ }^{2}$

${ }^{1}$ Smithsonian American Art Museum, Washington, District of Columbia, United States, ${ }^{2}$ Smithsonian Institution, Museum Conservation Institute, Suitland, Maryland, United States

The non-destructive nature of portable X-ray fluorescence (p-XRF) spectrometry and its ability to confirm elements through characteristic X-rays allows the technique utility in analyzing objects in cultural heritage, like paintings. However, analysis is generally performed in air which causes atmospheric scattering that results in low X-ray fluorescence yield for low atomic number elements such as $\mathrm{Na}, \mathrm{Mg}, \mathrm{Al}, \mathrm{Si}, \mathrm{P}, \mathrm{Cl}, \mathrm{S}$, and $\mathrm{K}$. With the lower atomic number elements underrepresented and the better X-ray fluorescence yield for elements with increasing atomic number; this can often present an analytical challenge in the identification of major concentration raw materials [1]. For example, even when $\mathrm{Pb}$ is not present as raw material as confirmed by scanning electron microscopy-energy dispersive spectroscopy (SEM-EDS); a significant Pb peak can be observed in an XRF spectrum (example shown in Figure 1). Additionally, paintings are commonly made up of multiple layers, which is complicated because XRF is a technique that penetrates beyond the top surface. Depending on the characteristic X-ray of interest element, the X-rays can come from 10s to 100s of microns from within the sample which is dependent on the material's compositional matrix [1].

In preparation for the "Fighter for Freedom" exhibition at the Smithsonian American Art Museum, pXRF was performed on the paintings Historical Scene and Crispus Attucks by African-American artist William H. Johnson, which was collected using a Bruker Elio with a Rh source in air. Samples were also collected for cross-sectional analysis by laboratory-based SEM-EDS. The samples were embedded polyester resin and harder and cross-sectioned with a Leica EM Trim. SEM-EDS was then collected at $20 \mathrm{kV}$ using a Hitachi S3700N SEM. Bruker Esprit 2.1 was used to process both p-XRF and SEM-EDS data. Of the data collected, five representative color regions were evaluated with both techniques from the Historical Scene painting (Figure 2A) and four representative color regions were evaluated with both techniques from Crispus Attucks (Figure 2B).Being that both sets of data were collected, an opportunity to use the findings from cross sectional SEM-EDS data to assist in developing methodologies to better interpret $\mathrm{p}$-XRF data of paintings presented itself.

From SEM-EDS, it was concluded that Historical Scene did not contain $\mathrm{Pb}$ as a raw material and Crispus Attucks had an underlayer that contained $\mathrm{Pb}$ and $\mathrm{Cr}$. Using net counts, $\mathrm{Cr} \mathrm{K} \alpha, \mathrm{Zn} \mathrm{K} \alpha$, and $\mathrm{Pb} \mathrm{L} \alpha$ peaks from $\mathrm{p}-\mathrm{XRF}$ were normalized against $\mathrm{Pb} \mathrm{L} \alpha$ net counts and the resulting ratios are presented in Table I. For the two paintings, values of $\mathrm{Zn} \mathrm{K \alpha}$ alpha/ $\mathrm{Pb} \mathrm{L}$ alpha when $\mathrm{Pb}$ is not present were $>2.47$; when is $\mathrm{Pb}$ is present as a pigment raw material in the top layer the values $<0.52$. For the red violet in Crispus Attucks, $\mathrm{Zn}$ is present in the both layers, with an underlayer containing both $\mathrm{Pb}$ and $\mathrm{Cr}$ at a calculated value of 1.71. For the blue in Crispus Attucks, the $\mathrm{Zn} \mathrm{K \alpha}$ ratio/ $\mathrm{Pb} \mathrm{L} \alpha$ ratio was 0.964 , with the $\mathrm{Pb}$ and $\mathrm{Cr}$ layer beneath the top layer. It should be noted that in this case study, the top-down p-XRF measurements alone will not allow for the identification of the underlayer containing $\mathrm{Pb}$ and $\mathrm{Cr}$ because the depth of $\mathrm{Cr} \mathrm{K} \alpha \mathrm{X}$-rays that were not detectable and $\mathrm{Pb} \mathrm{L} \alpha \mathrm{X}$-rays which were detectable are drastically different; this content will be presented in greater detail along with the supporting laboratory-based SEM-EDS data. 


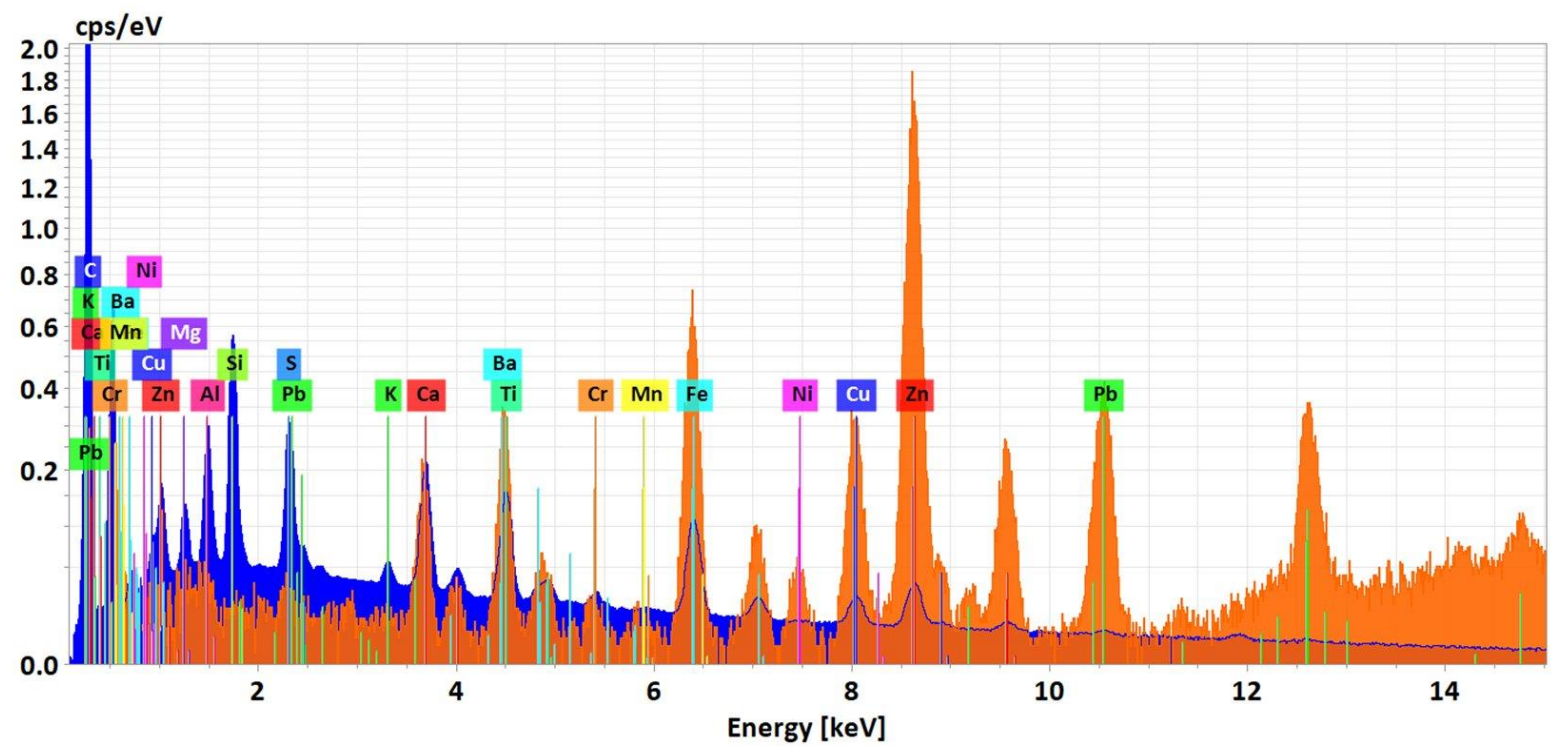

Figure 1. SEM-EDS sum spectrum from cross-section (in blue) and a representative p-XRF spectrum (in orange) for background blue graycolor region from the Historical Scene. Both Spectra were normalized to Ca and the $y$-axis is square root scaled. 

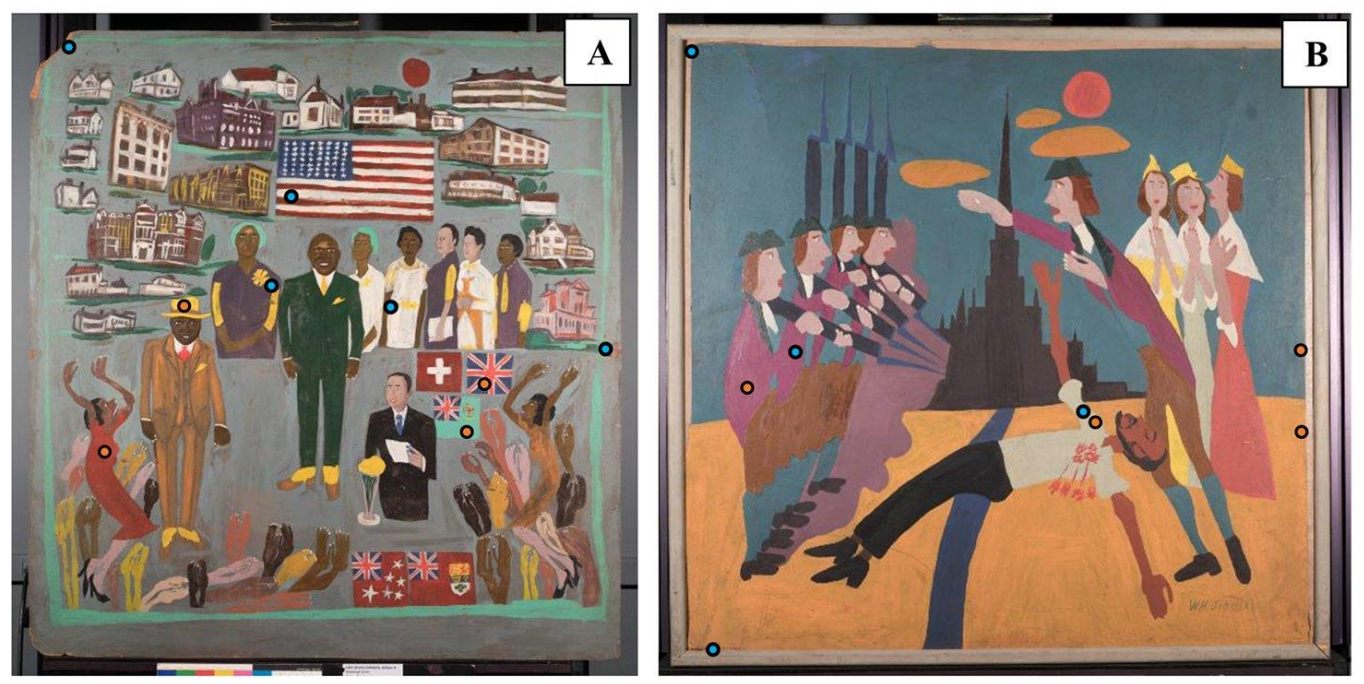

Table I. Corresponding Colors, SEM-EDS Cross Sectional Observations and Ratios from pXRF.

\begin{tabular}{|c|c|c|c|}
\hline & & & Data from $\mathrm{pXRF}$ \\
\hline & Color & SEM-EDS Cross Sectional Observations & $\mathrm{Zn} \mathrm{K \alpha /Pb} \mathrm{L} \alpha$ \\
\hline & Sea Green & No $\mathrm{Pb}$ present, $\mathrm{Zn}$ top layer & 51.184 \\
\hline$\stackrel{\vec{\Xi}}{.0}$ & Violet & no $\mathrm{Pb}$ present & 33.963 \\
\hline$\frac{2}{8}$ & Background (Blue-Gray) & no $\mathrm{Pb}$ present & 3.787 \\
\hline$\dot{\Sigma}=$ & White & no $\mathrm{Pb}$ present & 2.471 \\
\hline & Yellow & $\mathrm{Pb}$ and $\mathrm{Cr}$ in top layer & 0.274 \\
\hline & Red Violet & $\mathrm{Zn}$ in both layers, $\mathrm{Pb}$ and $\mathrm{Cr}$ in layer under & 1.710 \\
\hline$\frac{0}{3}$ & Blue & $\mathrm{Pb}$ and $\mathrm{Cr}$ in layer under & 0.964 \\
\hline$\underbrace{\frac{\pi}{3}}$ & Pale Green & $\mathrm{Pb}$ and $\mathrm{Cr}$ in top layer & 0.510 \\
\hline & Yellow & $\mathrm{Pb}$ and $\mathrm{Cr}$ in top layer & 0.104 \\
\hline
\end{tabular}

Figure 2. p-XRF locations in orange circles and SEM-EDS cross sections from in blue circles on (A) Historical Scene, accession \#1967.59.646, dimensions $99.3 \mathrm{~cm}$ x $94.3 \mathrm{~cm}$ (B) on Crispus Attucks, accession \#1983.95.53, dimensions $74.9 \mathrm{~cm}$ x $78.4 \mathrm{~cm}$. Table I of corresponding colors, SEM-EDS cross-sectional observations and ratios from $\mathrm{p}-\mathrm{XRF}$.

\section{References}

[1] M. Haschke, Laboratory Micro-X-Ray Fluorescence Spectroscopy: Instrumentation and Applications. Springer (2014). 